\section{Formação em Comunicação Social, currículo e práticas de extensão universitária}

\section{Márcio Simeone Henriques}

Professor e pesquisador. Departamento

de Comunicação Social. Universidade

Federal de Minas Gerais, Brasil.

simeone@ufmg.br
Integración de la docencia y la extensión /

Desafíos de gestión

RECEPCIÓN: 24/06/16

ACEPTACIÓN FINAL: 04/09/16

\section{Resumo}

O artigo discute o papel das práticas extensionistas para a formação em

Comunicação Social no Brasil, diante das intensas transformações nas formas contemporâneas de comunicação e na prática deste campo profissional, bem como do contexto de implantação de novas diretrizes curriculares nacionais para os cursos da área. Partindo da ideia de uma relação intrínseca entre extensão e comunicação, destaca uma posição privilegiada que a prática comunicacional ocupa na produção e efetividade das ações de extensão e, em sentido inverso, as possibilidades e limites para uma visão mais integrada e orgânica da extensão aos projetos pedagógicos.

\section{Resumen}

El artículo aborda el papel de las prácticas de extensión para la formación en Comunicación Social en Brasil dadas las profundas transformaciones en las formas contemporáneas de la comunicación y en las prácticas de este campo profesional, así como en el contexto de implementación de nuevas directrices curriculares nacionales para los cursos. Desde la idea de una relación intrínseca entre extensión y comunicación, pone de relieve una posición privilegiada que ocupa la práctica comunicativa en la producción de las acciones de extensión y, por el contrario, las posibilidades y los límites de una visión más integrada y orgánica de extensión a los procesos de enseñanza.

Palabras-clave

- Extensión

- Comunicación

- Educación

- Currículo

Para citación de este artículo 


\section{Introdução}

A área de Comunicação Social tem conhecido, nos últimos anos, uma grande mudança, tanto nas práticas profissionais quanto em seu projeto de formação no Brasil. Desnecessário dizer do grande significado que as inovações correntes nos meios, com a rápida e crescente evolução tecnológica dos dispositivos digitais, dão nova forma às diversas práticas sociais, culturais e políticas contemporâneas. De modo mais específico, tendem a provocar grandes transformações nos fazeres tradicionais associados às profissões típicas (Jornalismo, Publicidade e Propaganda e Relações Públicas). De outra parte, o meio acadêmico brasileiro também se vê diante de outro desafio, qual seja, o de reorganizar os projetos político-pedagógicos à luz de diretrizes curriculares nacionais para a área da Comunicação Social, recentemente estabelecidas pelo Conselho Nacional de Educação. As normativas são uma modificação muito substantiva na forma de conceber a formação e seu enquadramento nas profissões típicas, especialmente porque altera a lógica estruturante dos cursos - não mais de Comunicação Social com habilitações correspondentes às profissões, mas agora desdobrados, eles próprios, em cursos autônomos. ${ }^{1}$

Essa alteração geral, com uma série de exigências específicas trazidas pelas diretrizes, força uma grande reestruturação para todos os cursos do país e tem colocado em primeiro plano uma discussão crucial a respeito do sentido da profissionalização e o papel da educação superior diante das renovadas práticas comunicacionais da sociedade e da reconfiguração dos processos e das instituições midiáticas. Assim, é no contexto de uma acesa polêmica acerca da adequação e da pertinência dessas diretrizes que os cursos da área se defrontam com o desafio de conceber inovações didático-pedagógicas e pensar nas formas de alinhamento entre teorias e práticas, bem como das dimensões de ensino, pesquisa e extensão.

O presente artigo pretende refletir brevemente acerca de alguns elementos fundamentais para a compreensão da extensão no processo formativo no âmbito da Comunicação Social. Para além dos desafios impostos pelo contexto, encontra-se aí uma oportunidade para, ainda uma vez, reforçar as noções de extensão universitária que vêm sendo cultivadas no Brasil e na América Latina como sendo, essencialmente, um processo comunicacional, o que traz a prática extensionista a uma condição de não apenas ser um coadjuvante no processo educativo e, mais ainda, conduz a uma percepção do papel peculiar que a própria comunicação possui para a efetividade dos projetos.

Neste sentido, nossa argumentação está proposta em três momentos: (a) o reconhecimento da contribuição da extensão à formação superior, como postulada na perspectiva brasileira;

(b) uma reflexão acerca do lugar da comunicação na prática da extensão e

(c) inversamente, sobre o lugar da extensão na formação em comunicação. Com isso queremos ressaltar a posição peculiar (e, por que não dizer, privilegiada) da área da comunicação, quando vista pelo prisma da extensão e, desta forma, reiterar a importância de um investimento pedagógico e institucional amplo de docentes e discentes da área em tais processos.

\section{Contribuição da extensão à formação acadêmica}

Muito se fala, de modo genérico, sobre a contribuição dos projetos de extensão universitária para a formação do estudante da educação superior, o que pode ser evidenciado de diversas formas, qualquer que seja a área de conhecimento. Sob o ponto de vista pedagógico, é inegável que a extensão pode prover um conjunto de experiências significativas que não podem ser alcançadas pela didática tradicional em sala de aula, uma riqueza vivencial que estimula o aprendizado e dá sentido imediato a reflexões teóricas e à aquisição de técnicas.

É notório que essa contribuição nem sempre é valorizada e que há inúmeras contradições em relação à aplicação da extensão na formação, incluindo uma concepção meramente clientelística, destinada tão somente a oferecer uma oportunidade de prática profissional, na aquisição de habilidades, via prestação de serviços. Mesmo reconhecendo que essas práticas tenham seu lugar nas complexas práticas formativas, já é firme a concepção de que não podem representar todo o escopo da extensão. Por outro ângulo, temos que destacar que a densidade da contribuição das atividades extensionistas é variável e que a extensão, por si mesma, não é necessariamente uma oportunidade de vivência significativa, capaz de agregar valor didático-pedagógico.

A noção de extensão largamente cultivada na América Latina e, mais especialmente, no Brasil, tem uma pretensão significativamente
1) As Diretrizes Nacionais para os Cursos de Jornalismo foram aprovadas pelo Conselho Nacional de Educação (CNE) em 27 de setembro de 2013. [Recuperado de http:// portal.mec.gov.br/index.php?option=- com_docman\&view=download\&alias $=14242$-rces001-13\&category_slu$\mathrm{g}=$ setembro-2013-pdf\&ltemid=30192 (10/05/2016)]. Também as de Relações Públicas foram aprovadas na mesma data. [Recuperado de http://portal. mec.gov.br/index.php?option=com_docman\&view=download\&alias $=14243$-rces002-13\&category_slu$\mathrm{g}=$ setembro-2013-pdf\&ltemid=30192 (10/05/2016)], porém, as de Publicidade e Propaganda ainda sequer foram elaboradas. Pelas resoluções, os cursos tiveram prazo de dois anos para se adaptarem, pedagógica e administrativamente, às novas diretrizes, para os novos ingressantes. 
maior do que um repasse de conhecimentos produzidos na academia. Trata-se de inseri-la como fator essencial da vida acadêmica, não apenas articulável com as dimensões de ensino e pesquisa, mas como o próprio vetor de articulação entre eles. Isso está expresso, por exemplo, no Plano Nacional de Extensão, de 1999, que remete a uma função da extensão de viabilizar a relação transformadora entre universidade e sociedade por meio do processo articulador que ela institui com as outras dimensões (Forproex, 2001).

Sem dúvida, essa perspectiva é eminentemente política e esbarra nas formas de operação do modelo organizacional da ciência e da educação — portanto, das universidades. A adoção de uma visão como esta preside a proposta de um modelo de ciência, de educação e de universidade e define o escopo das relações com a sociedade que, em si mesmo, comporta um desafio epistemológico - quer seja na construção de uma "pedagogia da autonomia", na proposta de Paulo Freire (1996), quer para a implementação de uma "epistemologia do sul", postulada por Boaventura de Sousa Santos (2004). Pode-se dizer que, mais que um horizonte normativo, o Plano Nacional de Extensão formula um horizonte ético e, por que não dizer, nos convoca à utopia.

Se aceitarmos essa provocação, estaremos diante de escolhas paradigmáticas fundamentais. De modo resumido, somos desafiados a sair de um modelo articulador onde ensino, pesquisa e extensão possuem funções estritamente definidas em relação ao conhecimento (onde à pesquisa cabe a produção do conhecimento, ao ensino cabe a sua didatização e à extensão a sua mais ampla difusão) (Fig. 1) para outro em que essas funções estão presentes em todas as três dimensões (obviamente de formas diferentes, segundo suas particularidades). Além disso, é mais coerente substituir a ideia de difusão pela ideia de compartilhamento, tal como se postula em termos de interação dialógica e de apropriação autônoma do saber (Fig. 2).

\section{Fig. 1}

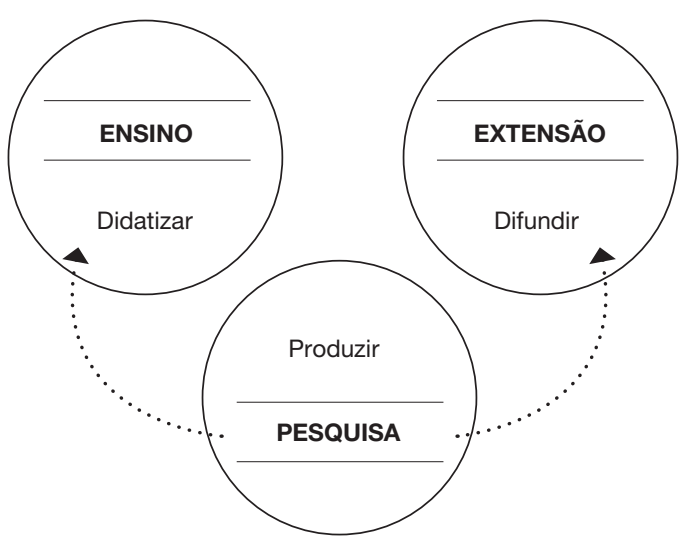

Fonte: elaborada pelo autor

\section{O lugar da comunicação na extensão}

Desde a obra clássica de Paulo Freire - "Extensão ou Comunicação?" (1983)— temos sido provocados a pensar na relação comunicativa constituinte de uma proposta de extensão. Isso nos conduz a um raciocínio muito particular para a área: o da comunicação em sua contribuição para a extensão universitária. Ainda que seja numa visão difusionista e meramente transmissiva, há uma demanda evidente pelo manejo instrumental de meios e processos de comunicação (criação visual e textual, de sites, de produtos de áudio e vídeo, de panfletos, de jornais, de instrumentos de convocação e mobilização social etc.). Isso já nos permite dizer que as atividades de cunho extensionista nessa área não são delimitadas apenas pela extensão de técnicas e práticas de comunicação ou das reflexões críticas acerca dos processos midiáticos, ou seja, do que seria o saber-fazer propriamente comunicacional e da forma crítica de pensar a comunicação e seus meios. Há um outro nível de demanda que se configura pelo caráter comunicacional (e relacional) da extensão, por si mesma. A ideia de transformação social e diálogo, impressa no Plano Nacional de Extensão, não apenas nos remete ao caráter comunicativo da extensão, segundo o Forproex (2007) "marcada pelo diálogo, pela ação de mão-dupla, de troca de saberes" (18), como também ao seu caráter público de ação "voltada para os interesses e necessidades da maioria da população e implementadora de desenvolvimento regional e de políticas públicas" (18). A estreita relação entre o caráter comunicativo e o caráter público se dá por meio de um conjunto de interações no âmbito dos projetos e que pretendem promover o envolvimento e o engajamento dos seus públicos. Isso ocorre principalmente naqueles projetos voltados para a resolução coletiva de problemas, onde se postula um envolvimento participativo e cooperativo e que têm como desafio alcançar a participação e a cooperação e criar, portanto, vínculos com os públicos (Henriques, 2013).

Fig. 2

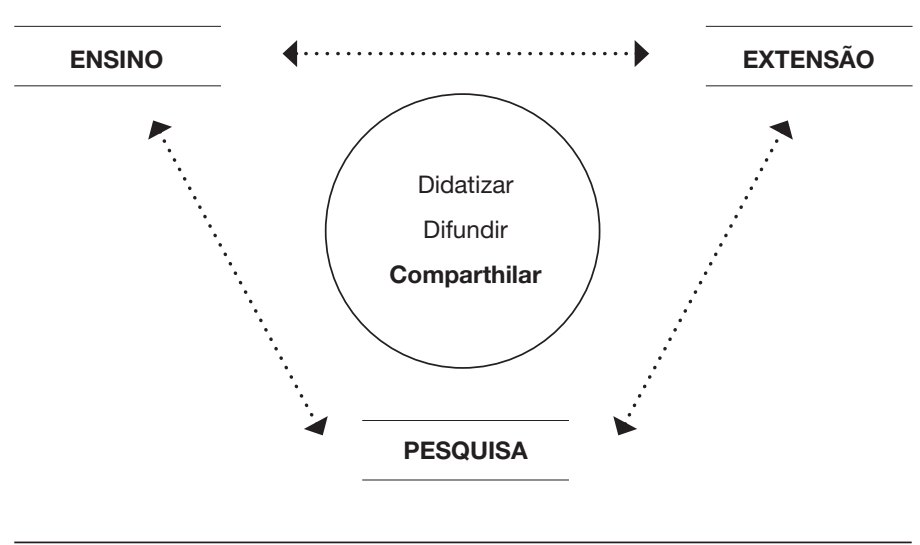

Fonte: elaborada pelo autor

| Revista +E 6 | 2016 | pp. 138-145 
Projetos específicos da área de comunicação costumam contemplar o trabalho com diversos tipos de grupos e comunidades em termos de produção midiática —-tradicional ou nas mídias digitais- assessoria social, leitura crítica ou acesso público às mídias. Entretanto, há também muitas outras iniciativas que atendem a demandas de projetos extensionistas muito variados, em qualquer área do conhecimento. Seria, mais ou menos, como tratar a comunicação na extensão tanto como fim quanto como meio. Sem menosprezar de forma alguma a importância, a conveniência e a necessidade dessas ações finalísticas, há que reconhecer também que uma abordagem mediadora é riquíssima e abre infinitas possibilidades de inserção social muito substantiva. E também destaca a área da Comunicação no cenário da extensão por esses aspectos peculiares. Essa condição particular da área a coloca em posição muito vantajosa para exercer a extensão numa perspectiva de fato interdisciplinar, ampliando o espaço de criatividade e de colaboração. Assim, muitos projetos podem contemplar as demandas de suporte $e$ assessoria a qualquer projeto de extensão, podendo contribuir em grande medida no apoio às relações comunitárias e aos processos de mobilização social que esses projetos pretendem estabelecer. ${ }^{2}$ Há que apontar aqui uma dificuldade em relação aos modos de fomento, que não costumam contemplar essa peculiaridade. No Brasil, os editais internos das universidades, bem como o Proext/MEC ${ }^{3}$, principal fomentador das ações de extensão, costumam contemplar a área de comunicação em sua dimensão finalística (mesmo assim, nem sempre é possível delimitar com maior precisão os enquadramentos que fazem). Por outro lado, nem todos os projetos de outras áreas, embora demandem intensivamente as ações de comunicação, costumam reservar recursos ou bolsistas para essas ações ou sequer recorrem ao auxílio e suporte de pessoas da área de comunicação e seus cursos. Quando isso ocorre, muitas vezes é apenas parcialmente, o que traz severas limitações nas possibilidades de ação. E ainda, mesmo que ocorra de modo satisfatório, em termos de recursos, muitos projetos são impermeáveis à ideia de maior interação e colaboração com os públicos, o que também constrange as propostas mais interativas e dialógicas que possam ser feitas pela Comunicação. Mesmo com todas as limitações, nota-se um avanço na direção da constituição de um lugar mais amplo para a área de Comunicação nesses processos.

\section{O lugar da extensão na formação em comunicação}

Como podemos perceber, a extensão pode ocupar um lugar especial na formação em Comunicação Social. De fato, muitas experiências articuladas com o ensino têm sido feitas historicamente nos cursos brasileiros, por meio da realização de atividades em disciplinas práticas com o viés extensionista. Trazemos aqui brevemente, a título de exemplo, o caso do curso de Comunicação Social da Universidade Federal de Minas Gerais, no Brasil. Desde a implantação do Currículo 2000, a definição das atividades didáticas práticas que são denominadas laboratórios contempla expressamente seu caráter extensionista.

A implantação da flexibilidade curricular, tendência observada há duas décadas, produziu efeitos no sentido de valorizar a atividade de extensão realizada pelos alunos, produzindo acreditação (atribuição de créditos curriculares). Isso impulsionou os cursos a admitir diferentes modalidades didáticas e, com isso, possibilitar uma melhor articulação com a extensão. Tomando como exemplo ainda mais específico os projetos da área de Comunicação executados no âmbito de um dos maiores programas de extensão da universidade, o Programa Polo de Integração da UFMG no vale do Jequitinhonha, essa acreditação tem-se efetivado de várias formas, seja em projetos próprios da área de comunicação, seja pela participação de docentes, discentes e técnicos em projetos de outras áreas de conhecimento. A tabela 1 mostra as oito modalidades curriculares que envolvem essas atividades de extensão e o envolvimento de discentes, no período de 2001 a 2015. ${ }^{4}$ Por certo, a efetivação de todas essas modalidades depende fortemente do envolvimento dos docentes na sua promoção e de uma visão mais abrangente e conectada dessas atividades.
2) Henriques (2013) destaca, neste sentido, a importância dos processos de mobilização social e o papel da comunicação na criação de vínculos entre os sujeitos e instituições e na geração e manutenção de laços comunitários, formando um caráter público dos projetos de extensão universitária. 3) O Proext é o Programa Nacional de Extensão Universitária e tem caracte- rísticas e financiamento interministerial no âmbito do Governo Federal, sob coordenação do Ministério da Educação, criado em 2003 e com ênfase na inclusão social [Recuperado de portal.mec.gov.br/index.php?option=com content\&view=article\&id=12241\&ativo=488\&ltemid=487 (13/05/2016)] Pelas suas características intersetoriais e com múltiplas fontes de financiamen- to que variam por período orçamentário, a cada edital anual do Programa são criadas categorias diferentes às quais os projetos precisam se enquadrar. Assim, projetos de comunicação, também por sua característica múltipla, por vezes precisam competir com outros projetos de áreas muito diferentes, e sob critérios de avaliação que nem sempre são adequados.
4) A tabela inclui apenas estudantes matriculados no curso de Comunicação Social, em qualquer de suas habilitações. Há que registrar também a participação de alunos de outros cursos da Universidade em projetos da Comunicação. 


\section{6}

a implantação da flexibilidade

curricular, produziu efeitos no

sentido de valorizar a atividade de

extensão realizada pelos alunos

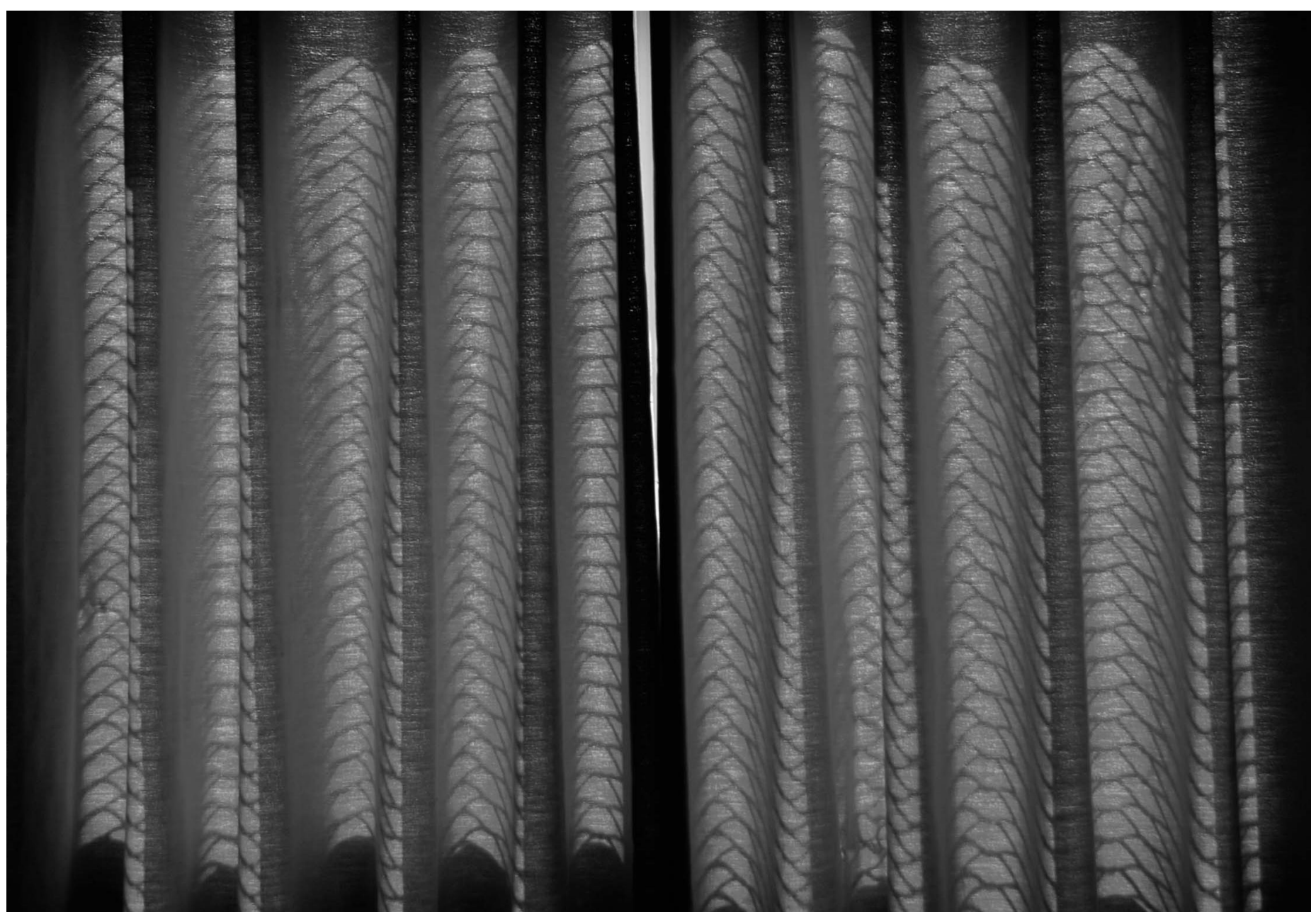

(c) Laura Hormaeche 
Tab. 1

\begin{tabular}{|c|c|}
\hline $\begin{array}{l}\text { Modalidades de acreditação curricular } \\
\text { de atividades de extensão do Programa } \\
\text { Polo de Integração da UFMG no Vale } \\
\text { do Jequitinhonha }\end{array}$ & $\begin{array}{l}\text { Discentes participantes } \\
(2001 / 2015)\end{array}$ \\
\hline \multirow[t]{2}{*}{ Estágios remunerados } & 74 (em projetos de comunlcação) \\
\hline & 16 (em projetos de outras áreas) \\
\hline \multirow[t]{2}{*}{ Estágios voluntários } & 87 (em projetos de comunicação) \\
\hline & 23 (em projetos de outras áreas) \\
\hline Iniciação Científica & 03 \\
\hline Laboratórios/disciplinas práticas (7 ofertas) & 59 \\
\hline Discussões temáticas (3 ofertas) & 38 \\
\hline Cursos de extensão (5 ofertas) & 34 \\
\hline $\begin{array}{l}\text { Apresentação de trabalhos científicos } \\
\text { em eventos ( } 15 \text { trabalhos) }\end{array}$ & 27 \\
\hline $\begin{array}{l}\text { Trabalhos de conclusão de curso } \\
\text { (5 trabalhos) }\end{array}$ & 09 alunos \\
\hline
\end{tabular}

Fonte: Programa Polo Jequitinhonha (UFMG)

Podemos levantar aqui alguns pontos críticos em relação à extensão no âmbito da formação, tendo em vista as novas diretrizes curriculares da área. Em consonância com o nosso raciocínio anterior, atividades de extensão deveriam ter um papel fundamental como prática organicamente constituinte da formação. As novas diretrizes nacionais para os cursos de Jornalismo estabelecem que a estrutura do bacharelado deve:

"utilizar metodologias que privilegiem a participação ativa do aluno na construção do conhecimento e a integração entre os conteúdos, além de estimular a interação entre o ensino, a pesquisa e a extensão, propiciando suas articulações com diferentes segmentos da sociedade". (Conselho Nacional de Educação, 2013) $)^{5}$

Embora abra essa perspectiva para articulações inovadoras e contemple o conjunto de atividades de pesquisa e de extensão realizadas pelos estudantes na avaliação do curso, as próprias diretrizes tendem a ver as práticas da extensão como um apêndice, ou seja, "como necessários prolongamentos das atividades de ensino e como instrumentos para a iniciação científica e cidadã". ${ }^{6}$ Com isso, inscreve essas práticas, do ponto de vista curricular, como atividades complementare. ${ }^{7}$

É fato que este modelo que preside a elaboração e aprovação de diretrizes para a educação superior por parte da Secretaria de Educação Superior do Ministério da Educação e do Conselho Nacional de Educação — pelo menos na área das Ciências Sociais Aplicadas- é um modelo fechado, baseado essencialmente em atividades didáticas tradicionais (mesmo que sob o constante apelo retórico à flexibilidade do currículo). As justificativas para uniformização passam pelos argumentos de forçar a qualidade dos cursos, especialmente os de instituições isoladas (majoritariamente instituições privadas), que não possuem alta margem de flexibilidade nem o grau de autonomia didática que possuem os centros universitários e as universidades, especialmente as instituições públicas. Com isso, essas diretrizes passam ao largo das possibilidades de inovação didáticopedagógica. Um grande problema é, então, o de promover mudanças didáticas efetivas que incorporem toda uma nova realidade, não apenas dos fazeres da comunicação, em suas profissões ou fora delas, mas também da sociedade.

O problema da incorporação da extensão como atividade regular e remunerada, com a incidência de uma carga horária considerada extraclasse - de difícil computação numa lógica produtiva cuja docência se baseia na regência - constitui um obstáculo à sua adoção pelas instituições de ensino privadas. Em termos mais gerais, há um obstáculo para a inserção orgânica da extensão num modelo educacional produtivista e que ainda é baseado na hipervalorização das atividades didáticas tradicionais de aula. Também nãos e pode negligenciar o problema da disponibilidade dos próprios discentes, principalmente dos cursos noturnos, o que acaba sendo tomado como um fator inibidor das iniciativas de extensão e limitando o percurso formativo às clássicas atividades de aula, numa didática tradicional.
5) Conforme a Resolução 01 de 27/09/2013 do Conselho Nacional de Educação [Recuperado de http:// portal.mec.gov.br/index.php?option= com_docman\&view=download\&alias=14242-rces001-13\&category_slu- g=setembro-2013-pdf\&ltemid=30192 (09/05/2016)].

6) Conforme o item II do Artigo $2 .^{\circ}$ da mencionada Resolução. 7) Conforme o parágrafo $5 .^{\circ}$ do Artigo 13 da referida Resolução. Note-se que as diretrizes para os cursos de Relações Públicas seguem o mesmo caminho, sem diferenças significativas no que se refere à inserção das práticas de extensão. 


\section{Considerações finais}

No atual momento, estamos diante de inúmeros desafios. Face à nova realidade imposta pelas novas diretrizes curriculares nacionais, destacamos pelo menos três, que demandam urgente atenção:

(a) Tornar mais orgânicos e mais efetivos os mecanismos de inserção curricular da extensão - a formulação de novos projetos político-pedagógicos para os cursos da área de Comunicação Social ensejam a oportunidade de prever princípios pedagógicos claros que incorporem uma noção abrangente de extensão e também requerem a constituição de projetos de ensino articulados (à pesquisa e à extensão).

(b) Do ponto de vista administrativo, é fundamental que se insira a extensão nos processos de avaliação docente e departamental, não apenas de modo figurativo e auxiliar, mas com pleno efeito em termos de produção acadêmica. É interessante notar que um grande passo neste sentido foi dado no Brasil a partir da valorização do critério de inserção social na avaliação dos cursos de pós-graduação do país. Vale dizer que este quesito foi inserido na ficha de avaliação periódica dos mestrados e doutorados, que no Brasil é realizada pela Coordenação de Aperfeiçoamento de Pessoal de Nível Superior (CAPES), órgão do Ministério da Educação. Tem peso fixo de $10 \%$ no caso de mestrados acadêmicos e doutorados e de 10 a $20 \%$ no caso de mestrados profissionais. Isso implica numa avaliação de impacto social dos programas de pós-graduação, o que, em grande medida, se materializa na relação com a extensão universitária, sendo, em princípio um dos seus indicadores mais relevantes. Isso está inscrito, de modo genérico, no Plano Nacional de Pós-Graduação 2011-2020 (Brasil, 2010). ${ }^{8}$

(c) Em termos didáticos, assume fundamental relevância (e urgência) a discussão acerca de práticas inovadoras no ensino da Comunicação. Isso não pode se dar apenas no sentido de revitalizar a sala-de-aula, mas de repensar os formatos de ensinoaprendizagem vigentes, que seguem sendo essencialmente disciplinares. A proposta extensionista pode ser, neste sentido, fomentadora de novas práticas didáticas e, mais além, instigadora de uma nova pedagogia.

Acreditamos que a prática da extensão, para além de uma visão simplista, pode ser a provedora de um lugar de experimentação —no sentido de gerar possibilidades aos estudantes de vivências e experiências que não poderiam ter de outras maneiras. Não se trata apenas de experiência profissional, mas uma experiência de vida, de encontro com um mundo pouco ou nada conhecido, fora dos universos de sua experiência mais imediata e trivial. O mais interessante aqui é a criação de um compromisso de aprendizagem (entre docentes e discentes), uma espécie de pacto cognitivo. Isso se complementa pelo papel protagonista que o estudante pode ter nessas práticas. Assim, além de defrontar-se com o diferente e com as diferenças, precisa lidar de modo proativo com elas, na solução de problemas comuns. Nisso, sem dúvida, reside a possibilidade de cumprir a promessa de formar profissionais com ampla visão de mundo e num viés crítico.

\section{Referências bibliográficas}

Forproex - Fórum de Pró-Reitores de Extensão das Instituições Públicas de Educação Superior Brasileira (2001). Plano Nacional de Extensão Universitária. Ilhéus/ BA: Editus.

Forproex - Fórum de Pró-Reitores de Extensão das Instituições Públicas de Educação Superior Brasileira (2007). Extensão Universitária: organização e sistematização. Belo Horizonte: Coopmed.

Freire, P. (1983). Extensão ou Comunicação? ( $8^{\circ}$ ed.). Rio de Janeiro: Paz e Terra. Freire, P. (1996). Pedagogia da autonomia: saberes necessários à prática pedagógica. São Paulo: Paz e Terra.

Henriques, M.S. (2013). A dinâmica da comunicação para a mobilização social nas práticas da extensão universitária. Interfaces-Revista de Extensão da UFMG, 1(1), 24-34

Ministério da Educação, Coordenação de Aperfeiçoamento de Pessoal de Nível Superior e Brasil. (2010). Plano Nacional de Pós-Graduação 2011-2020. Brasília: Capes.

Sousa Santos, B. de (2004). A universidade do Século XXI: para uma reforma democrática e emancipatória. São Paulo: Cortez.
8) Não obstante, convém destacar que o Documento de Área 2013 da Capes para as Ciências Sociais Aplicadas (onde se encontra a Comunicação), no item relativo à inserção social, não menciona de forma taxativa a extensão universitária entre seus indicadores de avaliação. Recuperado de https:// www.capes.gov.br/images/stories/ download/avaliacaotrienal/Docs_de_ area/Ciencias_Sociais_Aplicadas_doc area_e_comiss\%C3\%A3o_16out.pdf (13/05/2016). 


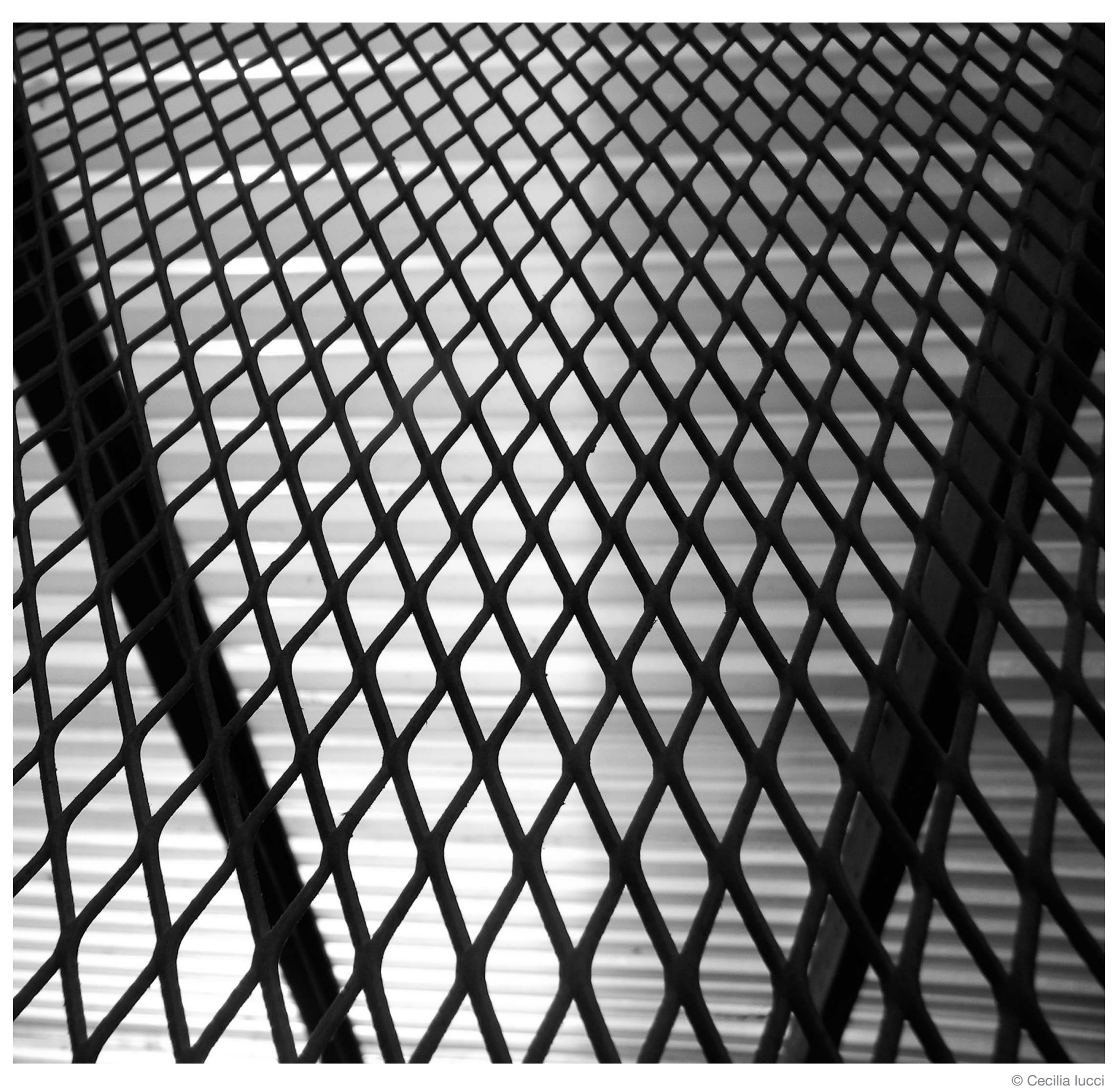

